v. 14, n. 1

Vitória-ES, Jan-Feb. 2017

p. 1-20 ISSN 1808-2386

DOI:http://dx.doi.org/10.15728/bbr.2017.14.1.1

\title{
A Design Management Framework for the Fashion Industry
}

\author{
Cláudia de Souza Libânio ${ }^{\dagger}$ \\ UFCSPA \\ Fernando Gonçalves Amaral ${ }^{\Omega}$ \\ UFRGS
}

\begin{abstract}
Organizations have been demonstrating an interest to invest in design, perceiving it as a strategic element to obtain competitive advantage. Design must become an integral part of the corporate objectives, permeating all levels of corporate activities. For this reason, this paper aims to propose a framework based on concepts of competences by checking and assessing their applicability in design management in the apparel industry. This study included conducting a literature research, through the development of a systematic literature review as well as an exploratory study with a qualitative approach, through the use of in-depth interviews. This proposed framework was then exposed to the evaluation of specialists. After this assessment, adjustments were suggested, resulting in the final proposal of the framework for training and integration of individuals and teams in design management for companies in the apparel industry, supported by the concepts of competence. This framework identifies phases and design professional activities that are crucial for the occurrence of design management and are related to product development process, articulating the organizational strategies and the market research. By using the framework, we expect design to affect all organization levels, being present in the stages of the development process in a collection.
\end{abstract}

Keywords: Design Management; Competences; Framework; Apparel Industry.

*Author for correspondence:

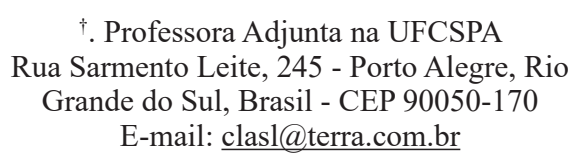

$\dagger$. Professora Adjunta na UFCSPA Grande do Sul, Brasil - CEP 90050-170 E-mail: clasl@,terra.com.br

\author{
$\Omega$. UFRGS \\ Av. Paulo Gama, 110 - Bairro \\ Farroupilha - Porto Alegre - Rio Grande \\ do Sul. CEP: 90040-060 \\ E-mail: amaral@producao.ufrgs.br
}

Note from the Editor: The article was accepted by Bruno Felix. 


\section{INTRODUCTION}

$\mathrm{T}$ Today, interest in design research related to strategy and management in companies is increasing. Ever more, design is seen as a multidisciplinary activity, that interacts with several levels and structures within organizations (BERTOLA; TEIXEIRA, 2003; CHIVA; ALEGRE, 2009; DELL'ERA; VERGANTI, 2010; RAVASI; STIGLIANI, 2012), being the theme of debates and studies related to design management (LIBÂNIO; AMARAL, 2011). The Design Council (2015) conceptualizes design management as the total activity of design, from the implementation and organization of new products and services development process to management and the achievement of better business performance.

The Portuguese Design Center (CPD, 1997) however, separates in two ways the performance of design management within companies: one, in the sphere of the Project, where the manager has the function of managing people, services and products during all stages of the project; and another, in the company's plan in its entirety, in which the manager will encourage, favorably, the creation of new products. With respect to corporate levels, Best (2006) states that design management should place design on a global level in the organization, taking into account the strategic, tactical and operational levels.

\section{LITERATURE REVIEW}

\subsection{DESIGN MANAGEMENT IN THE APPAREL INDUSTRY}

Inserted in the textile and clothing production chain, the apparel industry holds particular characteristics, as the proximity to the end consumer and the high number of agents involved in their production systems, through outsourcing. This last factor, while requiring self-management control of the production process, enables the rapid product development process.

In the global context, Brazil is among the four major producers of textiles (ABIT, 2010), the South Region of the country is the second largest textile Brazilian producer, second only to the Southeast Region (ABRAVEST, 2014). According to the Ministry of Labor and Employment, the more than 98,000 formal industries in Brazil employ more than 600,000 workers (ABIT, 2010). In this context, the apparel industry in the state of Rio Grande do Sul represents more than 7,500 of these industries and employs around 21,000 workers (ABIT, 2010). To determine the segmentation of markets, factors such as age, gender, social groups and income levels are analyzed (ABRAVEST, 2014).

In past times, the apparel industry was not encouraged to prioritize aspects such as design, quality and technology in their products. With increasing competition, the entry of new products in the Brazilian market and the advancement in communications technologies, consumers have 
become more demanding, and the market was forced to review their strategies. Thus, companies of the apparel industry began to direct their focus to market movements, such as logistical and technological advances, rapid time of creation, development and promotion of products, emphasis given to replacing production for products with higher added value, making use of design, technology and innovations.

Currently, the life cycles of clothing products are increasingly shorter because, in addition to the three standard annual collections, some companies create intermediate collections, systematically renewing the products in retail. The dynamism of the clothing market requires constant updates on raw materials, changes in colors and textures, innovations and new product launches to follow the trends of the industry. Thus, product development cycles need to be shortened to meet this dynamic. Thus, we observe the importance of design management, being involved from the development of strategies to the monitoring of the product's acceptance on the market, keeping a critical look at determining aspects related to processes, agents involved, knowledge and information.

International studies highlight the importance of the design team integration with the other participants of a project (REID et al., 2000; LAUCHE, 2005). Concepts of shared knowledge also appear (KLEINSMANN; VALKENBURG, 2008), competences of organizations and professionals (BRUCE et al., 1999; BELKADI et al., 2007), leadership in design teams (LEE; CASSIDY, 2007) and design as an agent of knowledge and integration in organizations (BERTOLA; TEIXEIRA, 2003; GIRARD; ROBIN, 2006) also appearing as factors related to design management. According to Libânio and Amaral (2013), certain aspects were first discussed abroad, being debated in Brazil later. Also according to the authors, characteristics such as leadership, autonomy, competences, entrepreneurship, proactivity, communication, integration and teamwork capacity were listed as essential requirements for design professionals.

\section{MODELS AND LEVELS OF DESIGN MANAGEMENT}

In order to systematize processes in companies, design management models are researched and constantly debated and rethought. A widespread understanding is the division of design management at three levels: strategic, tactical and operational (BORJA DE MOZOTA, 2003; BEST, 2006; ACKLIN, 2014). Borja de Mozota (2003) advocates that, at a strategic level, design is a core competency, connected to the company's strategy. At the tactical level, the design is an administrative competence and, at an operational level, it is understood as an economic competence. Best (2006) explains the design management in these three levels. At the strategic level, the tasks, plans and global policies are defined and must be connected with the design. At the tactical level, teams, processes and specific business units systems start relating to design. In the operational level, design management is manifested in physical and tangible products, services and experiences. 
When dividing design management into three levels, Borja de Mozota (2003) relates knowledge and network management and the strategy itself to the strategic level. At the tactical level, actions focused on the structure, management of technology and innovation are related. At the operational level, we find specific actions of brand marketing, production and communication. Another model is that by the author Best (2006), which identifies three design management stages: strategy, process and implementation. At first, the author states that design strategy inserts design thinking in organizational strategy. The design process however, is intended to make evident how the strategy can become visible and tangible through design. The design process consists of a series of methods brought together to meet the nature of the question or the design project. Finally, its implementation consists on how to transform the strategy and design processes into a final result (BEST, 2006).

Acklin (2014) entitles her model as the Lucerne Design Management Model and gives it the triangular shape, classifying the fundamental dimensions in the base, levels on the left side, the activities on the right side and actions of design management implementation within the triangle. The dimensions are subdivided into: leadership in design, design management and design thinking The levels are: strategic, tactical and operational. But the implementation of actions includes: planning, coordination and infusion. In a second triangle, which shows the design management processes that contribute to value creation through design, Acklin (2014) inserts essential processes, such as: management and brand design, corporate design management and development of new products and services. Control tools are also inserted, such as: philosophies, design policies and strategies, design programs and finally, stage-gates and key performance indicators.

CPD (1997) in turn, divides the design management in only two levels: strategic and operational. At the strategic level, the following aspects should be taken into account: the diagnosis of the company's situation, as well as its products and core technologies in relation to the closest competitors, the definition of the company's fields of activity in the future, the determination of the options depending on the strengths and weaknesses of the company, integration into the product development of the various areas involved, and design and innovation embedded in the business culture. At the operational level, the focus is placed on the activities of analysis and determination of the project's nature, selection of the work team and organization of the development process that establishes the extent of the phases and decision levels, ensuring an information flow to senior management and between team members.

Thus, we note that the literature presents design management models that show the importance of this issue for organizations. Nevertheless, we perceive the lack of a proposal to systematize this project, to facilitate its application and, consequently, the occurrence of design management. Thus, 
the research question is: how do we structure the training and the integration of individuals and teams for the occurrence of design management in the apparel industry?

\section{METHOD}

The present study involved a bibliographical literature research, through the development of a systematic literature review, as well as an exploratory research with a qualitative approach, using in-depth interviews. These research techniques were decisive for the development of the framework of training and integration of individuals and teams in design management for companies in the apparel industry, supported by the concepts of competences.

\subsection{Development of the proposal of the framework}

The proposal of a framework emerged from the definition of terms established in the literature. Wong and Aspinwall (2004) define framework as a set of basic assumptions or fundamental principles that form the basis for a given action. Aiding directly in decision-making processes and problem resolutions, the structure of the framework, according to Shehabuddeen et al. (2000), enables the comparison of different situations. The authors added that the framework enables the development of procedures, methods or techniques in order to translate these complex themes so they can be studied and analyzed.

For the development of the framework proposal, we conducted a systematic literature review, mapping out the relationships and connections between design management topics and competences, as well as identifying concepts that have relations with those themes, such as: learning, capabilities, resources, knowledge, value, interactions, communication, collaboration, market context, organizational culture, organizational structure, work processes and stakeholders involved. We adopted methodologies by Anderson et al. (2003), Alderson et al. (2004) and Biolchini et al. (2005) for the development of systematic literature review, relying on the NVivo9 and Mandala software to assist in the identification of these terms in the literature. From this analysis, the construction of a conceptual model emerged through the articulation and relationship of the concepts mentioned above. Subsequently, an exploratory survey was conducted with a qualitative approach, by conducting in-depth interviews with ten designers working in Brazilian companies belonging to the apparel industry and four specialists in fashion design.

In this study, we systematized the process of developing products for companies of the apparel industry and identified those involved in this process, as well as mapping out the phases and activities of the design professional, determinants for the occurrence of design management.

From the data collected in the systematic literature review and case study, we developed a proposal of framework for the training and integration of individuals and teams in the design management for companies of the apparel industry, supported by the concepts of competences. 
This framework was developed from the integration and coordination of the results arising from the research conducted.

\subsection{VERIFICATION, EVALUATION AND COMPLETION OF THE FRAMEWORK}

To check the structure and evaluate the applicability of the framework we assembled a group of specialists, consisting of three designers working in companies belonging to the clothing industry and two specialists in fashion design. The interviews with the five specialists were recorded and transcribed. The data were tabulated and analyzed using content analysis (BARDIN, 2005). We used a direct approach in the interviews and data were obtained from primary sources. To ensure the anonymity of the five respondents, they are identified in this study as: respondent 1 (R1), respondent 2 (R2), respondent 3 (R3), respondent 4 (R4) and respondent 5 (R5).

Throughout the interviews, the proposed framework was presented to the specialists, and they were free to analyze, criticize and suggest changes and/or propose new ideas, aiming to verify the structure and evaluate the applicability of the tool in question. Upon completion of the interviews, data were analyzed and considered for amendment and final assembly of the framework.

\section{RESULTS AND DISCUSSION}

From the examples of renowned designs management models (CPD, 1997; BRUCE; COOPER; VAZQUEZ, 1999; BORJA DE MOZOTA, 2003; BEST, 2006; ACKLIN, 2014) and studies performed by Libânio and Amaral (2011, 2013), we propose a conceptual model and a framework for training and integration of individuals and teams in design management for companies of the clothing industry, supported by the concepts of competences (individual, collective and organizational competences).

\subsection{THE CONCEPTUAL MODEL}

The conceptual model illustrated in figure 1 evidences relationships and associations between individuals, teams and organization, reaching out to the company's understanding as an open system.

The relationship between organizational structure and market context demonstrates the understanding that the external environment acts on the internal environment and, consequently, on the company's resources. As strategic resources for value creation in companies, Wernerfelt (1984) highlights that they may be physical, human and organizational beings, and "tangible or intangible assets". These resources can be: technology, information, people, knowledge, organizational routines, physical structure, brand, among others. Moreover, to create entry barriers in the market, 


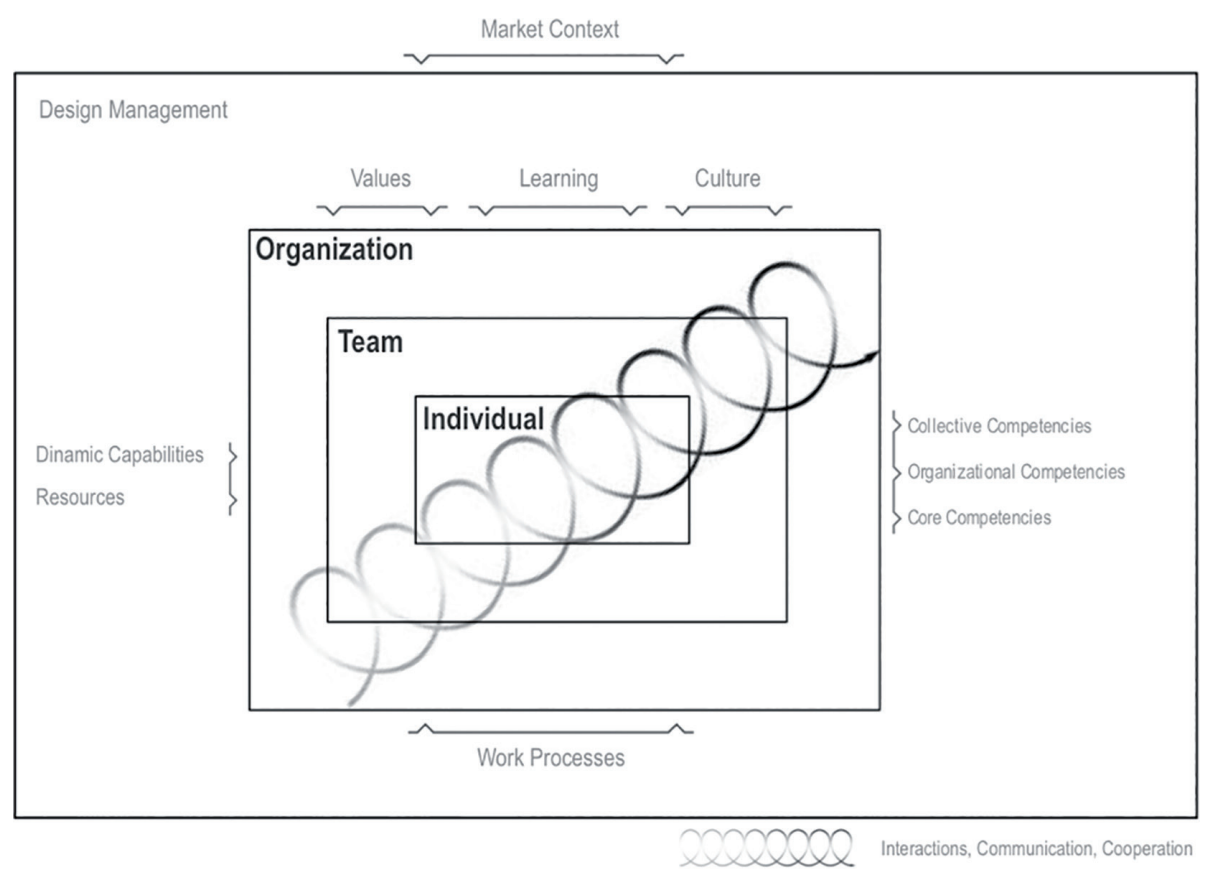

Figure 1. Conceptual model highlighting the connections between groups.

resources should be heterogeneous and immobile, presenting value attributes, rarity, difficulty of imitation and inability to replace (BARNEY, 1991). These resources are mobilized by the dynamic capabilities in ever-changing environments.

This external environment influences in the construction of core competence. Allied in this construction we find the dynamic capabilities, which are related to organizational routines and learning new skills and knowledge. Knowledge is also considered as a resource and incorporated into the organizational routines, both representing unique and specific resources of each company. The trend research routine in the apparel industry, or even the product development routine in consumer goods industries can be examples of collective practices and thus, unique and specific resources of companies. Nelson and Winter (1982) advocate that the routinization of the activities of a company is an important way to store specific knowledge of the organization. According to Michaux (2009), these organizational routines represent collective practices, resulting in organizational competences (organization's ability to perform a task successfully), and some of these eventually become strategic competences (amongst organizational competences, those that allow the company to gain a competitive advantage). New routines and knowledge encourage learning and hence the creation of new individual, collective and organizational competence, as well as core competences.

Another aspect that intervenes in this relationship of the conceptual model concerns the culture and organizational values, as: quality and excellence, ethics and respect, innovation and design. 
The understanding of design as a value for the company and its relationship with the mission and objectives of the company are in line with an organizational culture in harmony with the design, aiming at attaining sustainable competitive advantage.

\subsection{THE DEVELOPMENT PROCESS OF APPAREL PRODUCTS AND THE PHASES AND ACTIVITIES OF THE DESIGN PROFESSIONAL THAT ARE DETERMINANT FOR THE OCCURRENCE OF DESIGN MANAGEMENT}

Firstly, we have the definition of organizational strategies, that permeate all stages of the product development process. This process begins with the preparation of guidelines of the collection and its alignment with the company's strategies. We highlight that these strategies must be imbued with the sense of understanding design as a value by the company. Bruce et al. (1999) asserts that designers need information about the projects, such as market data, specifics of production, prices, plans and deadlines to be respected for better alignment with the initial briefing.

From the definition of the guidelines for the new collection and its products, the trend research stage occurs through the market monitoring, going through the creation, production of prototypes, production of the collection, review and quality control and distribution of goods to the monitoring of consumer satisfaction by the company.

Is worth mentioning that, with all the interviews grouped, we note the participation of some responsible for the design, either the designer or stylist or the director of the style department, in the stages of the product development process reported by respondents. It is noted further that each step requires data, information and competences that require the involvement of different individuals, teams, sectors and raw suppliers of materials and/or services, forming multidisciplinary teams. Chart 1 illustrates the phases and activities of the design professionals related to the product development process of companies of the apparel industry and key stakeholders.

Aiming at differentiating their products in order to achieve sustainable competitive advantage and following the dynamism of the clothing market, industry companies need to a prioritize phases and activities which are decisive for the occurrence of design management as a whole, such as:

i) the initial stage of setting guidelines and concept development for the new collection (Determinant Phase and Activity 1 - DPA1);

ii) the phase to research and identify trends and grouping of teams with different specialists for discussion and validation of collection (Determinant Phase and Activity 2 - DPA2);

iii) the defining moment to prototype, validate and start production of the collection as well as registering drawings and technical files (Determinant Phase and Activity 3 - DPA3); 


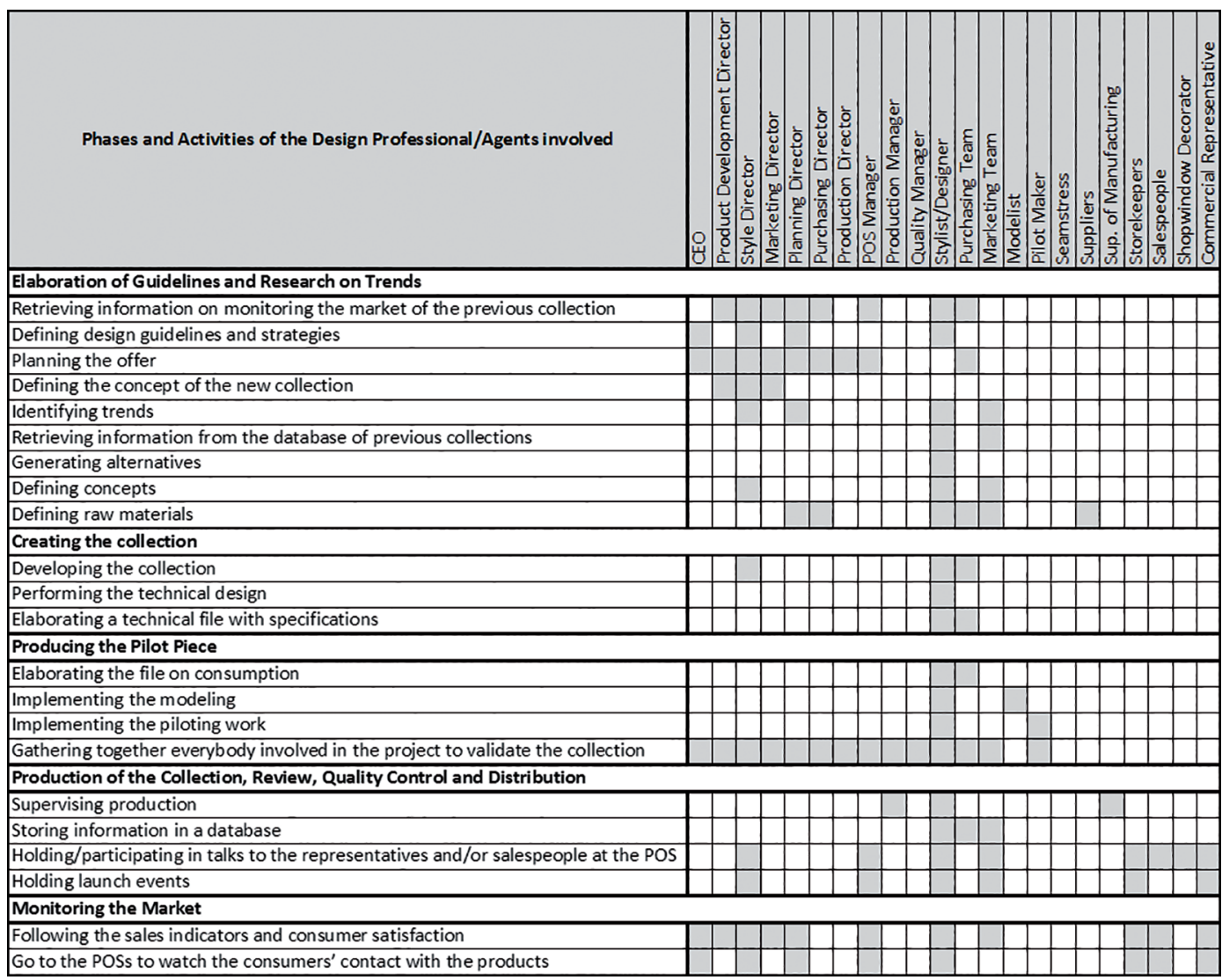

Chart 1. Phases and professional design activities related to the product development process of companies of the apparel industry and key stakeholders

iv) the phase of transmitting the mood, i.e., the concept of the new collection to managers, vendors and shopkeepers in retail outlets, and to business representatives (Determinant Phase and Activity 4 - DPA4);

v) market monitoring, through both data analysis and by direct contact with consumers in retail outlets or in virtual contacts (Determinant Phase and Activity 5 - DPA5);

vi) the moments of creation, exchange and retention of essential data and information, as well as the creation, development and retention of individual, collective and organizational competences (DPA1, DPA2, DPA3, DPA4 and DPA5).

\subsection{FRAMEWORK PROPOSAL}

Coupled with this identification, we proposed the integration of the conceptual model in the product development process and in the determinants phases and activities, aiming at promoting, through competences and related concepts, training and integration of individuals and teams in 
clothing companies. Therefore, we propose a framework for training and integration of individuals and teams in design management for these companies, supported by the concepts of individual, collective, and organizational competences.

For the assembly of the proposed framework in question, we began from the study of established models in the literature (CPD, 1997; BRUCE; COOPER; VAZQUEZ, 1999, BORJA DE MOZOTA, 2003; BEST, 2006; TREPTOW, 2007; MCKELVEY; MUNSLOW, 2008; RENFREW; RENFREW, 2009) and a study from the apparel industry. Together with the process of product development, we placed the five determinant moments. According to figure 2, the framework starts with the description and/or verification of the business, organizational culture and business objectives, aiming at aligning them with the design guidelines. Below, we present the project formatting stage, considering design as a value in its essence. The mapping of the product development process follows on, by identifying the inputs processes and outputs. From this mapping, the stakeholders who participated in the project should be defined, punctuating the competences and responsibilities required. In the product development process, phases and activities of design professional are punctuated, which are decisive for the occurrence of design management. Next, by applying the conceptual model, we perform the mapping of routines and competences to be developed and encouraged. Finally, we analyze possible impacts and constraints of the occurrence of design management, and we proceed to adjustments. It is important to note that before starting each project, that this framework be made suitable to the type of project that one intends to initiate.

\subsection{VERIFICATION, EVALUATION AND DEFINITION OF THE FRAMEWORK}

From the settings and findings of the specialists, the framework was reevaluated, with adjustments and corrections being made, in order to adapt the structure of the framework to make it applicable to the reality of companies of the apparel industry in Brazil.

\subsubsection{PHASES AND ACTIVITIES OF DESIGN PROFESSIONAL RELATED TO THE PRODUCT DEVELOPMENT PROCESS AND KEY STAKEHOLDERS}

Regarding the determinant phases and activities (DPA) of the design professional related to the product development process, illustrated in Chart 2, respondents in general, understood it as being made suitable to the apparel industry, and aligned to market dynamics. However, R2 suggested the insertion of the launch and promotion phase in this process, shortly after the approval of the collection's prototype by everyone involved. R2 highlighted that "preparation of advertising material must take place between the definition of the prototype and the release 


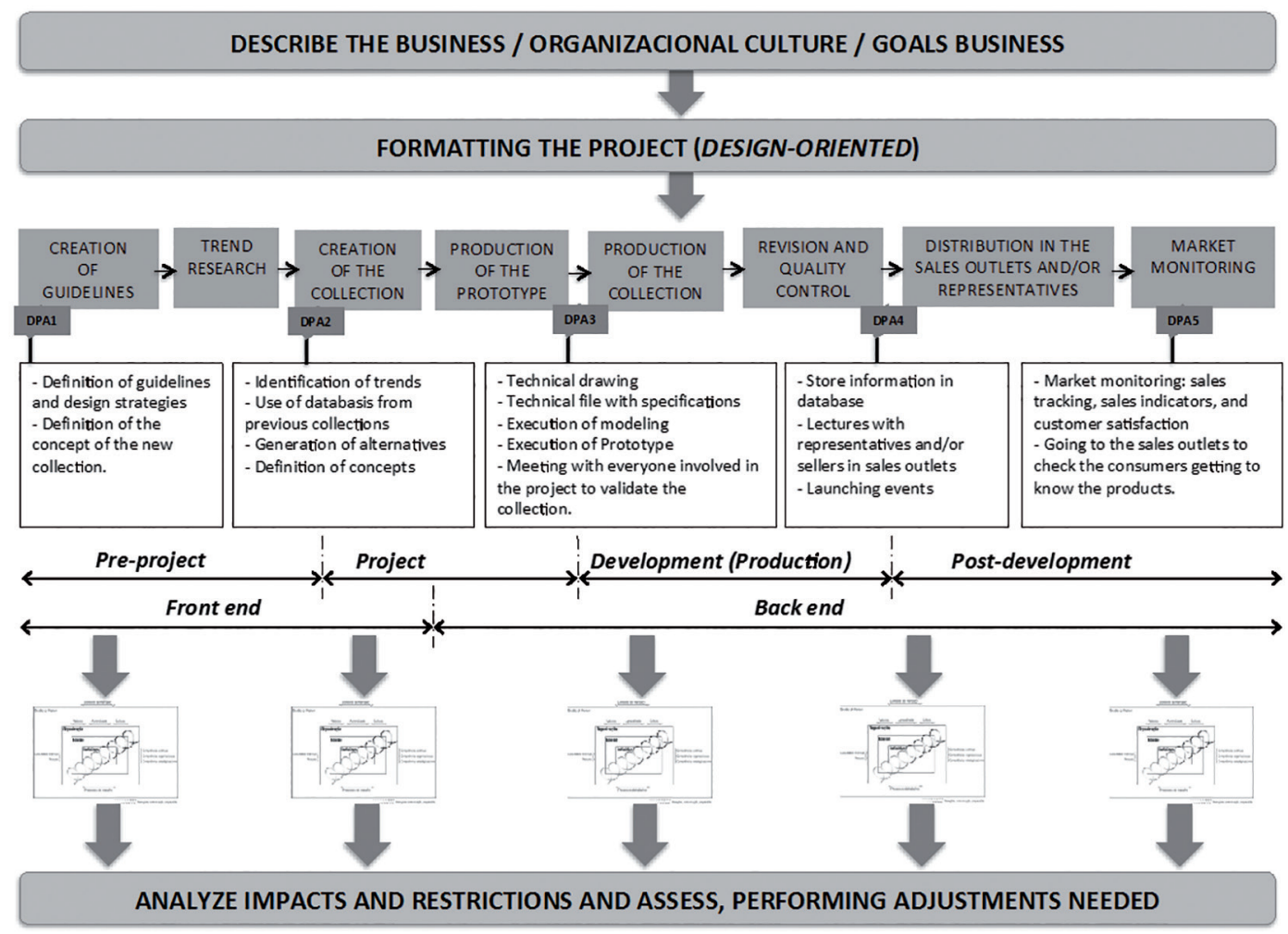

Figure 2. Framework for training and integration of individuals and teams in design management for companies of the apparel industry prior to the experts verification

and promotion of the collection on the market". Moreover, the respondent pointed out that the time for preparation of this material is short and therefore should be carefully planned. The task of communicating and promoting the new collection to sales representatives and retailers is set before it being distributed to these agents. However, R2 emphasized that "the launch and promotion should be anticipated to the previous step for large customers, despite being outnumbered, they strongly impact the sales of the collection". For this reason, it was deemed relevant and appropriate to insert this stage in the product development process.

Respondents were unanimous in agreeing that the design professionals have to participate and/or follow, direct or indirectly, all stages described in the product development process, as shown in Chart 2. This design professional is responsible for the understanding, the occurrence and encouragement of these integrated and multidisciplinary actions. Borja de Mozota (2003) advocates that the design management has two objectives: to train partnermanagers and designers, and develop methods to integrate design in organizations. Kotler and Rath (1984) emphasize that designers should participate in all stages of development of products, interacting with the areas involved in a particular project. Not only the design 


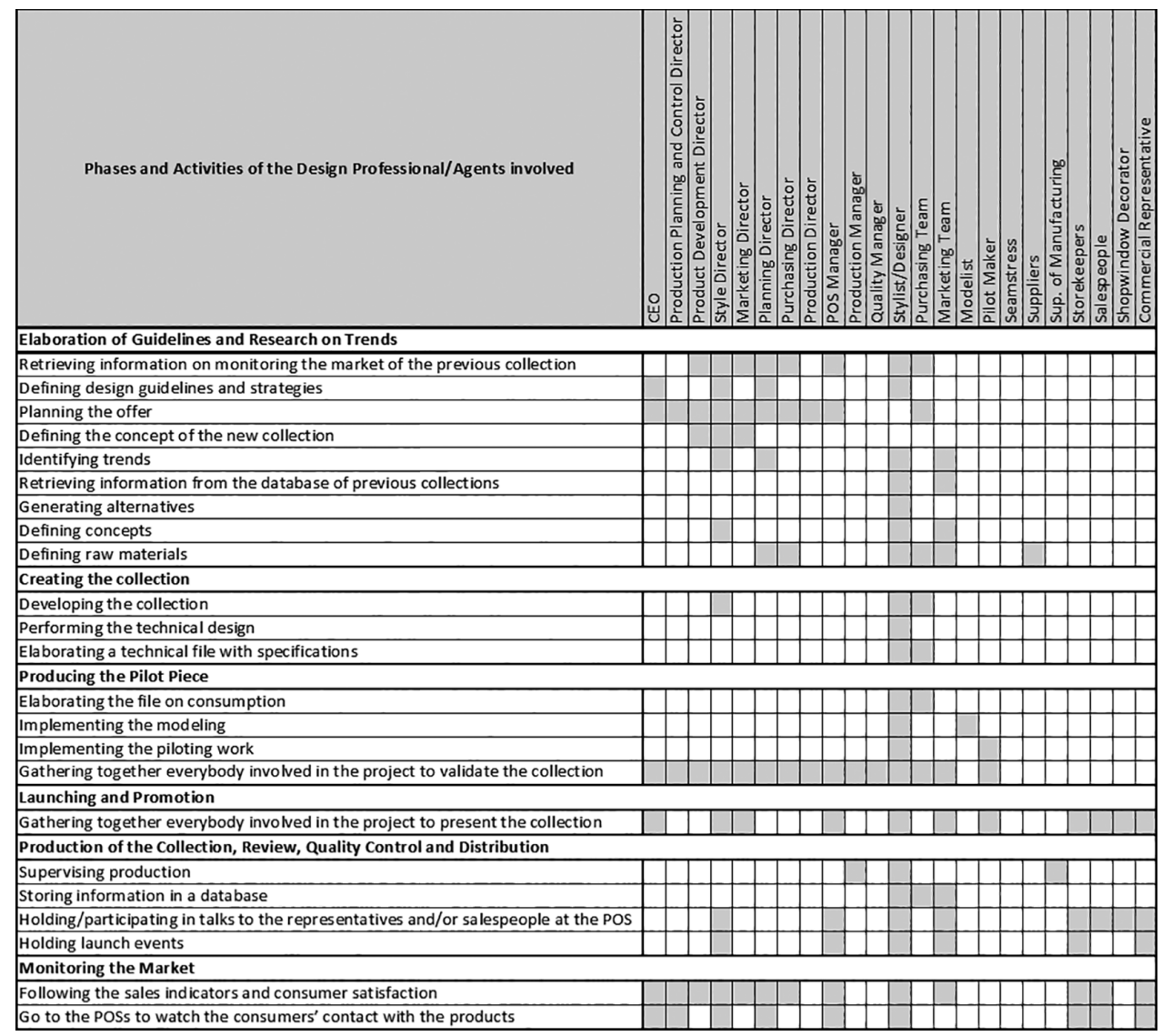

Chart 2. Phases and activities of the design professional related to the product development process of companies of the apparel industry and key stakeholders

professional, but all the teams involved in a particular project must share information, encouraging an integrated, collaborative and participative working environment.

Another point worth mentioning was the link between the marketing and design department in the apparel product development process. Respondent R3 highlighted that the synergy between these departments result in a systemic view, reaching out to the dynamism in the apparel and fashion market in general. R1 corroborates by stating that "marketing and design teams must have great communication and work together”.

The participation of some of those involved in the process was also worth the mention. R1 mentioned on the importance of the participation of the director of planning and production control (PPC) in the stage of developing guidelines, given that they are responsible for organizing deadlines and feasibility analysis of certain proposals. Regarding the purchasing director, R1 and R5 highlighted that this director must be present in the preparation of guidelines stage, because they are directly connected to suppliers, which are key elements to the negotiation of raw materials to be used in the new collection. But the executive director, 
according to the understanding of R1, must participate in the market monitoring stage for it is he/she who identifies products that should be discontinued or even remodeled to be included the next collection.

The role of design manager would be under the responsibility of the product development director, style director or designer, depending on the size and structure of the company. This manager, according to the CPD (1997), acts in two ways in companies' design management: one of them, in the project's sphere, the manager has the function of managing people, products and services for all stages of the project; and another, in the company's plan in its entirety, the manager will encourage favorably, creating new products. The functions and responsibilities of the design manager are directly related to the size and structure of companies. According to Pereira (2009), in large companies, the design manager has the task of supervising the teams engaged in each project, adapting to the particularities of each, and bearing a broad view of the business, encouraging integration between operational and strategic parts of the business. In small businesses however, the author highlights that, even by not performing the supervision of the business units, the design manager must seek actions that lead to the integration of project process with the objectives established by the company, regardless of its structure. Best (2006) states that the design manager needs to promote the best possible design strategy, thinking about the organization as a whole. The author also states that for that to happen, this professional should sensitize stakeholders on the relevance of this design strategy for the company. It is important to note that despite the different sizes of companies, the design manager must have characteristics such as: leadership, entrepreneurship, vast technical knowledge, managerial skills, pro-active profile, capacity to coordinate, as well as being motivating and able to influence the team.

But the involvement of those responsible for the points of sales (POSs), as well as sales representatives was also a debated issue. R2 highlighted the importance of connecting the POS director with the company. He further states that it is essential for the purchasing department to be present in the market monitoring, because they will be responsible for products and raw materials replacement, should any go missing. For companies using sales representatives, R5 emphasized the importance of contact with representatives of the labor market and business customers. In this case, the representatives also play the role of monitoring the market, following the acceptance or not of the collection pieces, acting directly in product replenishment orders.

The comment on the insertion of the launching and promotion stage of the collection triggered the proposition of another PDA. The inserted phase was placed between the definition of the prototype and the release and promotion of the collection on the market. 
One of the design professional's actions related to this determinant stage, is the storage of information in databases, due to the approval and the completion of the prototype. These updated databases determine the smooth progress of the collection, either to supply information to those involved in the process, whether as a collective memory of the teams and the organization itself. Two other actions related to this phase are connected to the next step (launching and promotion of the collection): lectures with representatives and/or sellers at the point of sale and promotional launching even (fashion shows and/or media through vehicles such as radio, TV, social networks and the company's own website).

Thus, determining the phases for the occurrence of design management and activities of the design professional, upon verification and evaluation of the specialists, we can be listed as follows:

i) In the initial phase, related to the definition of strategies and guidelines for the concept of the new collection, data and information coming from the market monitoring must be redeemed. Guidelines and design strategies that are aligned with the organizational strategy, culture and values of the company must also be defined. In this manner, it will be possible to define the planning of supply and the concept of the new collection. (Determinant Phase and Activity 1 - DPA1);

ii) After the trends research and consulting the database system of collections previously developed alternatives are generated as well as defining concepts and raw materials to be used for the development of the new collection (Determinant Phase and Activity 2 - DPA2);

iii) Once the concept and design of the collection are created, the moment to detail this creation for the production of the prototype begins. Technical drawings are made, technical files with specifications, consumption record, preparation to prototype (to make the prototype) and modeling (Determinant Phase and Activity 3 - DPA3);

iv) The stage of grouping teams with different expertise for discussion and validation of collection is also considered a determinant step towards the occurrence of design management (Determinant Phase and Activity 4 - DPA4);

v) the launching stage of the collection does not only happen through promotional material but also by transmitting the concept of the new collection to managers, vendors and retailers in points of sales, and to business representatives. At this stage, information that still needs to be put in the system should also be stored, in order to have a complete database, since the details are already closed, and 
the collection is already being forwarded to (Determinant Phase and Activity 5 DPA5);

vi) the final phase is the market monitoring through both data analysis and indicators as by direct contact with consumers in the points of sale or in virtual contacts, mapping the acceptance of products on the market (Determinant Phase and Activity 6 - DPA6);

vii) the moments of creation, exchange and retention of critical data and information, and the creation, development and retention of individual, collective and organizational competences (DPA1, DPA2, DPA3, DPA4, DPA5, and DPA6).

\subsubsection{FINAL STRUCTURE OF THE FRAMEWORK}

The final structure of the framework, as shown in Figure 3, integrates the process of clothing products development with the positioning of the six phases as well as key activities during this process, also aligned and permeating organizational strategies and research and constant monitoring of the environment. Regarding the organizational strategies, R4 said they are at the macro level, permeating and taking part of the entire product development process. Moreover, R4 also pointed out there is a specific trend research for each collection, which is located on the second stage of the product development process. However, according to R4 and R5, there is also a constant research that design professionals and others directly involved in design management should conduct. R5 points out that those involved in design management should cultivate the habit of curiosity constantly, seeking information about other realities. These research activities and environment monitoring, according to the perception of R5, can occur through field studies, cultural probes, moments of external field work to see people and their habits, understand new dynamics of consumption, identify disruptive signals, or even the acquisition of information through websites, blogs, books or trends from international trips. And according to R4, such monitoring should be done constantly and incorporated into working practices and daily life, turning them into routines in the organization.

In this way, both the organizational strategies as environmental research and monitoring are in greater scope, as they are present on the day to day business and should be incorporated by design professionals. Thus, it is evident that the major phases and activities not only permeate the product development process, but are also constantly connected to organizational strategies and environment research. 


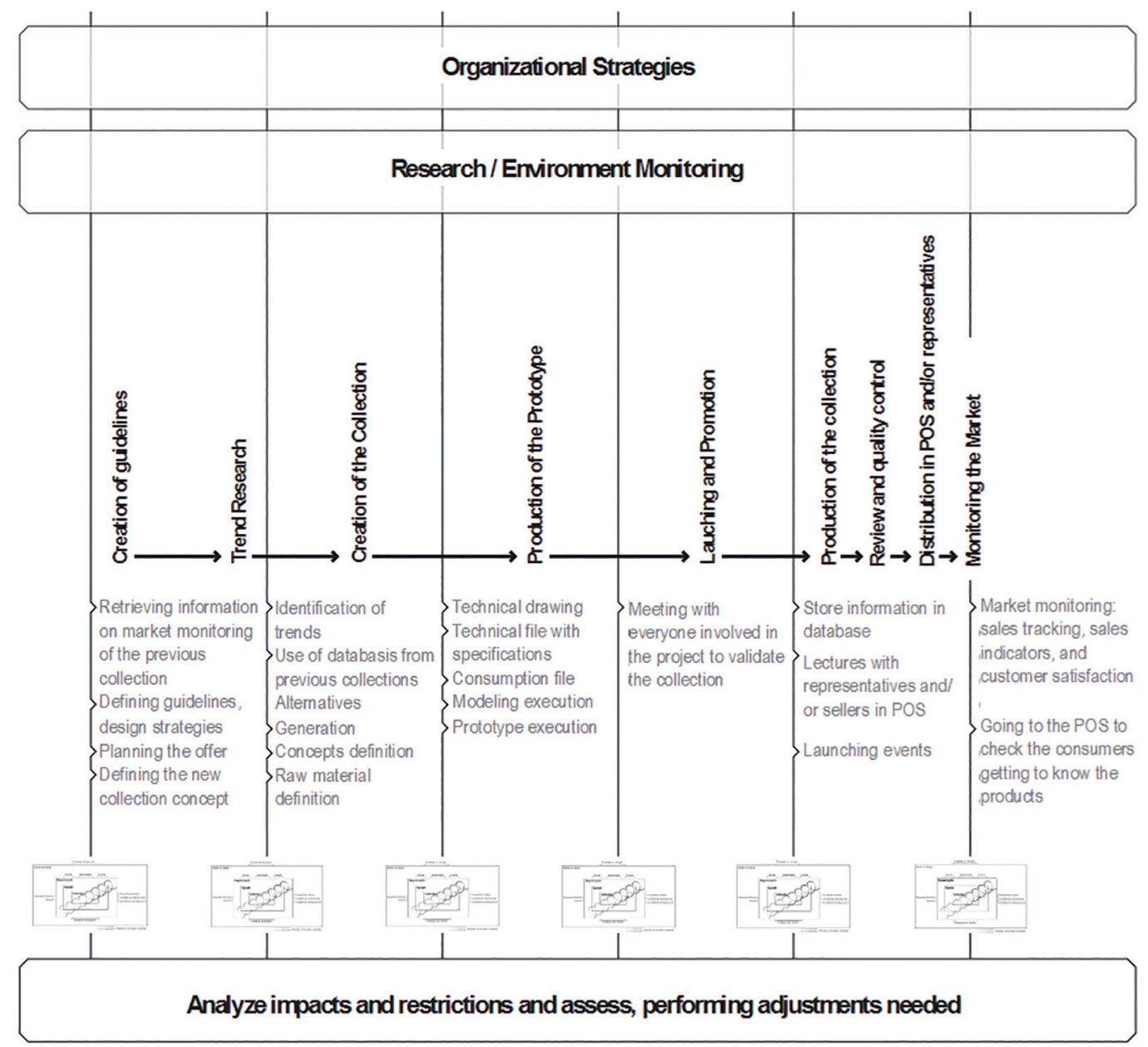

Figure 3. Framework for training and integration of individuals and teams in design management for companies of the apparel industry.

To assist in determining the occurrence of these six stages, we use the conceptual model, which aims to articulate the concepts related to competences, contributing to the training and encouraging the integration of individuals and teams in design management.

After determining each phase, from the application of the conceptual model, the analysis of impacts is indicated, evaluating constraints and performing adjustments if necessary. It is important, that before the start of any project that seeks to use this framework, for it to be analyzed and adapted to the specific type of project, if such adjustment is necessary.

\section{CONCLUSION}

This article aimed to propose a framework supported by concepts of competencies, verifying and evaluating its applicability in design management in the Brazilian apparel industry. The choice to study a Brazilian apparel industry was due to its particular 
characteristics, such as: the high representation in the economic and social context of the country, the proximity to the end consumer, the high number of agents involved in their production systems and the highly dynamic market. However, this industry has a vast field for the development of design management as well as the understanding of design as a strategic element for the sustainable competitive advantage.

Thus, the concepts of competence support the development of the framework, in order to assist in the training and integration of individuals and teams for the occurrence of design management. From the articulation of competences (at the individual, collective and organizational level) and related concepts, by applying a conceptual model of six phases during the development of a collection, the occurrence of design management is encouraged. The proposed framework identifies phases and activities of the design professional, which are determinants for the occurrence of design management and are related to the product development process, articulating the organizational strategies and environmental research. Moreover, the framework helps individuals involved to develop routines for determining the occurrence of design management, such as: the sharing of knowledge, the transformation of tacit knowledge into explicit, periodic storage of information in databases, the constant trends research and the monitoring of the external environment.

We expect that with the use of the framework, for design to affect all levels of the organization, being present in all stages of the development process of a collection. From a design empowerment path, in terms of business, the company will position itself in the system design and design plays a strategic role in the organization.

This research presents the application of limitation in a heterogeneous sample of companies inserted in the apparel sector, in terms of size, structure and service to the market. For future research, we suggest to conduct a study using a larger sample of companies, or in companies in other regions of Brazil. We also suggest the application of the framework through a quantitative research on companies located in the South, or in other regions of Brazil.

\section{REFERENCES}

ABIT - Associação Brasileira de Indústria Têxtil e de Confecções. PRADO, M.V. (org.). Brasil têxtil 2010: relatório setorial da indústria têxtil brasileira. São Paulo: IEMI, 2010.

ABRAVEST - Associação Brasileira da Indústria do Vestuário. Dados Estatísticos do Setor do

Vestuário. Disponível em <www.abravest.org.br>. Acessado em 29 de janeiro de 2014. 
ACKLIN, C. Disponível em: <http://www.academia.edu/191256/Lucerne_Design_Management Model>. Acesso em: 20 fev. 2014.

ALDERSON, P.; GREEN, S.; HIGGINS, J.P.T. Cochrane Reviewers' Handbook 4.2.2, Cochrane Library, Issue 1, Wiley, Chichester, UK, 2004.

ANDERSON, L.M.; et al. Methods for Conducting Systematic Reviews of the Evidence of Effectiveness and Economic Efficiency of Interventions to Promote Healthy Social Environments. American Journal of Preventive Medicine, V.24, 2003.

BARDIN, L. Análise de conteúdo. ed. rev. e atual. Lisboa: Edições 70, 2005.

BARNEY, J.B. Firm resourced and sustained competitive advantage. Journal of Management, v.7, n. $1,1991$.

BELKADI, F.; BONJOUR, E.; DULMET, M. Competency characterization by means of work situation modeling. Computers in Industry, v. 58, p. 164-178, 2007.

BERTOLA, P.; TEIXEIRA, J.C. Design as a knowledge agent: how design as a knowledge process is embedded into organizations to foster innovation. Design Studies, v.24, n.2, 2003.

BEST, K. Design Management: managing design strategy, process and implementation. Switzerland: Ava, 2006.

BIOLCHINI, J.; MIAN, P.G.; NATALI, A.C.C.; TRAVASSOS, G.H. Systematic Review in Software Engineering.Technical Report RT - ES 679/05, COPPE/UFRJ, 2005.

BORJA DE MOZOTA, B. Design Management: Using Design to Build Brand Value and Corporate Innovation. New York: Allworth, 2003.

BRUCE, M.; COOPER, R.; VAZQUEZ, D. Effective design management for small businesses. Design Studies, v. 20, 1999.

CARDOSO, M.A.; KISTMANN, V.B. Modularização e design na indústria automotiva: o caso do modelo Fox da Volkswagen do Brasil. Revista Produção Online, Florianópolis, v.8, n.4, 2008.

CHIVA, R.; ALEGRE, J. Investment in design and firm performance: the mediating role of design management. The Journal of Product Innovation Management. v.26, 2009.

CPD - Centro Português de Design. Manual de Gestão do Design. Porto, Portugal: 1997. 
DELL'ERA, C.; VERGANTI, R. Collaborative Strategies in Design-intensive Industries Knowledge Diversity and Innovation. Long Range Planning, v.43, p. 123-141, 2010.

DESIGN COUNCIL. Dísponível em: < www.designcouncil.org.uk > . Acessado em: 12 mar. 2015.

GIRARD, P.; ROBIN, V. Analysis of collaboration for project design management. Computers in Industry, v. 57, p. 817-826, 2006.

KLEINSMANN, M.; VALKENBURG, R. Barriers and enablers for creating shared understanding in co-design projects. Design Studies, v. 29, p. 369-386, 2008.

KOTLER, P.; RATH, A. Design: a powerful but neglected strategic tool. The Journal of Business Strategy, 5: 16-21, Fall, 1984.

LAUCHE, K. Job design for good design practice. Design Studies, v. 26, p. 191-213, 2005.

LEE, K.C.K.; CASSIDY, T. Principles of design leadership for industrial design teams in Taiwan. Design Studies, v. 28, p. 437-462, 2007.

LIBÂNIO, C.S; AMARAL, F.G. Aspectos da gestão de design abordados em dissertações e teses no Brasil: uma revisão sistemática. Revista Produção Online. Florianópolis, SC, v.11, n. 2, p. 565-594, 2011.

LIBÂNIO, C.S.; AMARAL, F.G. Design Professionals Involved in Design Management: Roles and Interactions in Different Scenarios: A Systematic Review. In: Chakrabarti, A.; Prakash, R.V. (eds.), ICoRD'13, Lecture Notes in Mechanical Engineering, DOI: 10.1007/978-81-322-10504_69, Springer India 2013.

MALHOTRA, N. Pesquisa de marketing: uma orientação aplicada. 6.ed. Porto Alegre: Bookman, 2012.

MCKELVEY, K.; MUNSLOW, J. Fashion design: process, innovation and practice. New York: Blackwell Science, 2008.

MICHAUX V. Articuler les compétences individuelle, collective, organisationnelle et stratégique: les éclairages de la théorie des ressources et du capital social. In: RETOUR D., PICQ T., DEFELIX C. (eds). Gestion des compétences: Nouvelles relations nouvelles dimensions. Paris: Vuibert - AGRH Gracco CNRS, 13-33, 2009.

NELSON, R.R.; WINTER, S.G. An Evolutionary Theory of Economic Change. Belknap Press of Harvard University Press: Cambridge, 1982. 
PEREIRA, D. Competências da Gestão Estratégica do Design no Pólo Moveleiro do Alto Vale do Rio Negro (SC). Dissertação (Mestrado). Universidade Técnica Federal do Paraná, Ponta Grossa, PR, 2009.

RAVASI, D.; STIGLIANI, I. Product Design: a Review and Research Agenda for Management Studies. International Journal of Management Reviews, 2012.

REID, F.J.M. et al. The management of electronics engineering design teams: linking tactics to changing conditions. Design Studies, v. 21, p. 75-97, 2000.

RENFREW, C.; RENFREW, E. Developing a Collection. Ava Publishing: Lausanne, 2009.

SHEHABUDDEEN, N.; PROBERT, D.; PHAAL, R. Representing and approaching complex management issues: part 1 - role and definition. WorkingPaper UC, Cambridge, 2000.

TREPTOW, D. Inventando moda: planejamento de coleção. 4ªed. Brusque: D.Treptow, 2007.

WERNERFELT, B. A Resource-based View of the Firm. Strategic Management Journal, v.5, 1984.

WONG, K.Y.; ASPINWALL, E. Knowledge Management Implementation Frameworks: A Review. Knowledge and Process Management, v.11(2), pp.93-104, 2004. 